\title{
RESEARCH
}

Open Access

\section{Clinical implementation of an oncology- specific family health history risk assessment tool}

Si Ming Fung ${ }^{1}$, R. Ryanne Wu ${ }^{2,3,4^{*}}$, Rachel A. Myers², Jasper Goh' ${ }^{5}$, Geoffrey S. Ginsburg ${ }^{2,3}$, David Matchar ${ }^{3,4}$, Lori A. Orlando ${ }^{2,3}$ and Joanne Ngeow ${ }^{1,5}$

\begin{abstract}
Background: The presence of hereditary cancer syndromes in cancer patients can have an impact on current clinical care and post-treatment prevention and surveillance measures. Several barriers inhibit identification of hereditary cancer syndromes in routine practice. This paper describes the impact of using a patient-facing family health history risk assessment platform on the identification and referral of breast cancer patients to genetic counselling services.
\end{abstract}

Methods: This was a hybrid implementation-effectiveness study completed in breast cancer clinics. English-literate patients not previously referred for genetic counselling and/or gone through genetic testing were offered enrollment. Consented participants were provided educational materials on family health history collection, entered their family health history into the platform and completed a satisfaction survey. Upon completion, participants and their clinicians were given personalized risk reports. Chart abstraction was done to identify actions taken by patients, providers and genetic counsellors.

Results: Of 195 patients approached, 102 consented and completed the study (mean age 55.7, $100 \%$ women). Sixty-six (65\%) met guideline criteria for genetic counseling of which $24(36 \%)$ were referred for genetic counseling. Of those referred, 13 (54\%) participants attended and eight (33\%) completed genetic testing. On multivariate logistic regression, referral was not associated with age, cancer stage, or race but was associated with clinical provider $(p=0.041)$. Most providers $(71 \%)$ had higher referral rates during the study compared to prior. The majority of participants found the experience useful $(84 \%)$, were more aware of their health risks (83\%), and were likely to recommend using a patient-facing platform to others (69\%).

(Continued on next page)

\footnotetext{
* Correspondence: ryanne.wu@duke.edu

Si Ming Fung and R. Ryanne Wu contributed equally to this manuscript.

${ }^{2}$ Centre for Applied Genomics and Precision Medicine, Department of

Medicine, Duke University School of Medicine, 304 Research Dr. Box 90141,

Office 264, North Carolina 27708 Durham, USA

${ }^{3}$ Department of Medicine, Duke University School of Medicine, 304 Research

Dr. Box 90141, Office 264, North Carolina 27708 Durham, USA

Full list of author information is available at the end of the article
}

C C The Author(s). 2021 Open Access This article is licensed under a Creative Commons Attribution 4.0 International License, which permits use, sharing, adaptation, distribution and reproduction in any medium or format, as long as you give appropriate credit to the original author(s) and the source, provide a link to the Creative Commons licence, and indicate if changes were made. The images or other third party material in this article are included in the article's Creative Commons licence, unless indicated otherwise in a credit line to the material. If material is not included in the article's Creative Commons licence and your intended use is not permitted by statutory regulation or exceeds the permitted use, you will need to obtain permission directly from the copyright holder. To view a copy of this licence, visit http://creativecommons.org/licenses/by/4.0/ The Creative Commons Public Domain Dedication waiver (http://creativecommons.org/publicdomain/zero/1.0/) applies to the data made available in this article, unless otherwise stated in a credit line to the data. 


\begin{abstract}
(Continued from previous page)
Conclusions: $65 \%$ of patients attending breast cancer clinics in this study are at-risk for hereditary conditions based on current guidelines. Using a patient-facing risk assessment platform enhances the ability to identify these patients systematically and with widespread acceptability and recognized value by patients. As only a third of at-risk participants received referrals for genetic counseling, further understanding barriers to referral is needed to optimize hereditary risk assessment in oncology practices.
\end{abstract}

Trial Registration: NIH Clinical Trials registry, NCT04639934. Registered Nov 23, 2020 -- Retrospectively registered.

Keywords: Genetic counselling, Hereditary cancer syndromes, Family history, Risk assessment, Referral

\section{Background}

The value of a precision medicine approach to clinical cancer care is becoming increasingly more evident [1] as advancements in genetic technology for sequencing and detection of somatic and germline mutations improve cancer treatment and prevention [2,3]. Given that 5 to $10 \%$ of cancer cases are hereditary, $[4,5]$ it is extremely important that patients with potential hereditary cancer syndromes are identified and offered genetic testing so that patients and their family members are aware of treatment options and subsequent steps to mitigate risk of additional cancers [2, 6-9]. For example, poly adenosine diphosphate-ribose polymerase (PARP) inhibitors are used to treat $B R C A$-associated advanced breast and ovarian cancers and are being evaluated for other cancer types [1, 10-12]. When considering surveillance and preventative measures following cancer treatment, those known to have a hereditary cancer syndrome have a wider range of potential measures that should be considered $[13,14]$.

However, barriers exist preventing widespread and effective adoption of systematic hereditary cancer screening in oncology $[15,16]$. Clinicians may be unfamiliar with clinical guidelines on when to refer patients for genetic counselling (GC), resulting in over and underutilization of cancer genetic services $[15,16]$. Although family health history (FHH) is essential for identifying at-risk individuals, [17-19] detailed FHH is rarely available in medical records and even less frequently available as structured data that providers can retrieve computationally [16, 20-22]. Hence, FHH collection relies largely on provider ascertainment during the clinical visit [19] but patients are frequently unprepared to provide $\mathrm{FHH}$, partly due to lack of communication among family members and/or lack of awareness of its importance [23]. Due to time constraints and lack of standardization and awareness, clinical providers may have difficulties maximizing the utility of $\mathrm{FHH}$ in their clinical practice to identify at-risk individuals [24].

Patient-facing FHH tools have been shown to be better than the current practice of FHH collection by clinicians $[19,25-29]$ and comparable to FHH collected by genetic counsellors [25]. Currently there are several software programs designed to facilitate identification of at-risk individuals; however, all prior evaluations were done within a primary care context and not one specific to oncology and the majority have not looked at clinical impact beyond risk identification [30].

MeTree, a web-based patient-facing FHH collection software with integrated clinical decision support (CDS), is one such platform [31]. MeTree has been extensively studied in primary care where it has been shown to increase risk identification and impact clinical care [3234]. We sought to evaluate how MeTree might be used to meet the needs of an oncology setting. After adapting the platform based on feedback from oncology and genetic counsellor study team members, we designed a pilot study to examine its impact in an oncology setting. This paper presents the primary implementation outcomes of risk identification and clinical referral impact.

\section{Methods \\ Overview and study design}

This was a hybrid type III implementation-effectiveness study [35] conducted at the breast oncology clinics of two hospitals in Singapore.

\section{Recruitment and enrollment}

All seven clinical providers (six medical oncologists and one breast surgeon) approached agreed to participate in the study. Eligible patients of these providers were offered enrollment face-to-face at their clinic appointments. The inclusion criteria were English-speaking patients with a histologically confirmed breast cancer who had not been referred for GC and/or testing. Written informed consent was obtained from the participants at recruitment.

\section{Intervention}

The MeTree risk assessment platform collects data on 128 medical conditions, including 32 cancers and 22 hereditary cancer syndromes, and analyzes seven cancer risk calculators (BRCAPro, Gail, MMRPro, TyrerCuzick, PREMM, and NCI's colon cancer risk calculator). MeTree provides CDS for 45 hereditary cancer syndromes and familial cancers in real-time via two reports: 
one for patients to highlight the high-risk aspects of their personal and $\mathrm{FHH}$ and points for discussion with their physician, and one for physicians that indicates the guideline recommendation and high-risk features that triggered the recommendation. Details regarding MeTree's initial development and validation have been published [31] Since it was initially developed for integration into U.S. primary care practices, study investigators and cancer clinic providers (clinicians and genetic counsellors), recommended several adaptations for oncology practices in Singapore (e.g. including Manchester risk score in decision support recommendations according to American College of Medical Genetics practice guidelines) $[17,36]$.

At study enrollment, participants were provided with: (1) Information about the importance of $\mathrm{FHH}$, and (2) $\mathrm{FHH}$ worksheet listing relative categories (e.g. siblings, aunts, uncles) with a description of the conditions collected in the risk assessment platform to facilitate $\mathrm{FHH}$ collection from relatives before entering their information into the software. Participants were scheduled to enter relevant personal history and $\mathrm{FHH}$ information into the risk assessment platform one-hour before their next clinic appointment using a study-provided electronic device. Educational resources were available within the platform and a coordinator was available to assist participants if needed. Both patient and provider reports were generated in real-time and reports were given to participants and providers. It was left up to the participant and their clinical provider whether to act on the recommendations provided.

Immediately post-risk assessment, participants completed a survey to assess their experience.

\section{Measures and outcomes}

Data were analyzed from two sources: data entered into and generated by the risk assessment platform and data from the electronic medical record (EMR). Platform data included: FHH pedigree data (including: number of relatives, \% of relatives with cancer diagnoses, age of disease onset), Manchester risk scores, clinical decision support recommendations, and triggers for GC recommendations. Pedigrees were assessed for (1) pedigree size, (2) the \% of relatives marked as having an unknown $\mathrm{FHH}$, and (3) the \% of relatives with cancer history, (4) the \% of relatives with cancer for whom age of onset was reported. The quality of the data was assessed by measuring the \% of relatives marked as having an unknown $\mathrm{FHH}$ and the \% of relatives with cancer for whom age of onset was reported. EMR data included: participant demographics, breast cancer details (age of diagnosis, years since breast cancer diagnosis, breast cancer stage, breast cancer type), GC referral status, and genetic testing results. GC referral status and genetic testing results were abstracted six months post-risk assessment. The primary outcomes were: (1) \% with a GC recommendation by risk assessment, and (2) among those with a recommendation the \% referred to a genetic counsellor by the clinical provider.

Secondary outcomes include participant responses in the post-risk assessment survey. The survey included 11 items with two being Likert scale items and the remainder yes/no categorical items. The survey was adapted from a previous study [37] and assessed the following areas: participant satisfaction, likelihood to recommend risk assessment platform to others, user experience of platform, preparedness of participants, overall experience and benefits from risk assessment platform.

\section{Statistical analysis}

Participant characteristics, risk assessment results, and $\mathrm{FHH}$ data were summarized using counts and percentages for categorical variables or means and standard deviations (SD) for continuous variables. Receipt of a GC recommendation ("GC recommendation" vs. "no GC recommendation") was examined for differences based on (1) participants' demographics, (2) FHH using Pearson's chi-square test for categorical variables, t-test for continuous participant characteristic variables, and Wilcoxon rank-sum test for FHH parameters (pedigree size, $\%$ relatives with unknown $\mathrm{FHH}$ \% relatives with cancer history, \% relatives with cancer for whom age of cancer diagnosis was reported). Among the subset of participants with a GC recommendation, receiving a GC referral ("GC referral" vs. "no GC referral") was examined for variation based on (1) participant demographics, (2) triggers for GC recommendation, and (3) provider, using Pearson's chi-square test for categorical variables and ttest for continuous variables. To test for differences in participant feedback on the post-risk assessment survey we analyzed survey responses by (1) FHH parameters using the Kurskal-Wallis test for Likert scale questions (satisfaction and likelihood to recommend) and Wilcoxon rank-sum test was used for the yes/no questions, and (2) GC recommendation using Pearson's chi-square test. Multivariate logistic regression fixed and mixed effect models were used to evaluate associations of participant demographics with GC recommendation and GC referral status of participants. All statistical analysis was conducted using $R$ statistical software, generalized linear mixed effect models were estimated using the $\mathrm{R}$ package lme4.

\section{Results}

Characteristics of participants

Of the 195 patients approached in breast oncology clinics from 7 January 2019 to 16 August 2019, 121 (62.1\%) consented to participate in the study and 102 
completed the study ( $84.3 \%$ of consented participants). Table 1 outlines key demographics of patients approached, consented and that completed the risk assessment. Among them, patients did not differ significantly in age, race, or breast cancer stage. Age of completed participants ranged from 39 to 81 years old; The racial distribution of completed participants was reflective of the Singapore population [38]. Breast cancer stage was normally distributed with $45.1 \%$ at Stage II. The mean age of diagnosis of completed participants was 52.5 years old, which is comparable to the median age of diagnosis in Singapore (53 years old) [39].

\section{Risk classification}

Sixty-six participants $(64.7 \%)$ met guideline criteria for GC recommendation. On univariate analyses, those with a GC recommendation were significantly younger ( 52.3 vs. $61.9, p<0.001)$, had a significantly younger age at breast cancer diagnosis ( 48.5 vs. $59.9, p<0.001)$, a significantly higher Manchester score (5.7 vs. 1.2, $p<$ 0.001 ), and a significantly longer duration since diagnosis (3.8 vs. 2.0, $p=0.004$ ) as compared to those without a GC recommendation. (Table 3) Race, breast cancer stage and assigned clinical provider had no significant impact on receiving a $\mathrm{GC}$ recommendation in univariate analyses. In multivariate logistic regression modelling, GC recommendation was associated with younger age (Odds Ratio (OR) -0.17, SE 0.05, $p<0.001$ ), having a higher Manchester score (OR 2.13, SE 0.10, $p<0.001$ ) and a higher percentage of relatives with cancer history (OR 1.14, SE 0.03, $p=0.03$ ) (Table 2).

\section{Risk evaluation}

Of the 66 participants with a GC recommendation, twentyfour $(36.4 \%)$ were referred for GC by their clinical providers. Age at enrollment, years since their breast cancer diagnosis, race, and breast cancer stage had no impact on GC referral. Some clinical providers were more likely to refer at-risk participants to GC than others $(p=0.04)$ (Tables 4 and 5). Among those referred, 13 (54.2\%) attended their GC appointments and eight (61.5\% of those who attended) underwent genetic testing. Of those tested, one had a pathogenic variant, five had Variants of Uncertain Significance (VUS), and two had benign variants. (Fig. 1)

\section{FHH data entered by participants}

Details of $\mathrm{FHH}$ entered by participants are provided in Table 3. Within FHH pedigrees, participants listed a mean of 10.7 relatives in their pedigree, a mean of $28.9 \%$ of relatives had unknown FHH and majority of cancer-affected relatives had age of onset reported (93.2\%). Those with $\mathrm{GC}$ recommendation had a trend towards higher \% relatives with cancer history (Mean: $16.9 \%$ vs. $12.0 \%, p=$ 0.09 ). There was no significant difference in the number of relatives entered or the quality of the $\mathrm{FHH}$ data entered (i.e. \% relatives with unknown $\mathrm{FHH}, \%$ relatives with age of cancer diagnosis reported) between those who did and did not receive a $\mathrm{GC}$ recommendation.

The clinical justifications for the GC recommendations are listed in Table 6. The most common clinical justification was a personal age of breast cancer diagnosis less than 50 years $(n=41 / 67)$ and an elevated Manchester risk score $(n=13 / 67)$. There was no obvious difference

Table 1 Characteristics of patients approached, patients consented and completed participants

\begin{tabular}{|c|c|c|c|c|}
\hline Characteristics & $\begin{array}{l}\text { Patients } \\
\text { approached } \\
(n=195)\end{array}$ & $\begin{array}{l}\text { Participants consented } \\
(n=121)\end{array}$ & $\begin{array}{l}\text { Participants completed risk } \\
\text { assessment } \\
(n=102)\end{array}$ & $p$-value ${ }^{\mathrm{a}}$ \\
\hline Mean age at $\mathrm{BC}$ diagnosis (SD) & $52.9(9.1)$ & $53.1(9.2)$ & $52.5(9.2)$ & 0.891 \\
\hline $\begin{array}{l}\text { Mean years from BC diagnosis to date } \\
\text { approached (SD) }\end{array}$ & $3.5(4.2)$ & $3.5(3.6)$ & $3.2(3.7)$ & 0.991 \\
\hline Race & & & & 0.959 \\
\hline Chinese & $129(66.2)$ & $81(66.9)$ & $67(65.7)$ & \\
\hline Malay & $40(20.5)$ & $20(16.5)$ & $17(16.7)$ & \\
\hline Indian & $13(6.7)$ & $8(6.6)$ & $7(6.9)$ & \\
\hline Others & $13(6.7)$ & $12(9.9)$ & $11(10.8)$ & \\
\hline Overall Breast Cancer Staging & & & 0.952 & \\
\hline 0 & $5(2.6)$ & $5(4.1)$ & $4(3.9)$ & \\
\hline । & $32(16.4)$ & $21(17.4)$ & $20(19.6)$ & \\
\hline$\|$ & $74(37.9)$ & $51(42.1)$ & $46(45.1)$ & \\
\hline III & $25(12.8)$ & $12(9.9)$ & $12(11.8)$ & \\
\hline IV & $38(19.5)$ & $19(15.7)$ & $17(16.7)$ & \\
\hline Unknown & $21(10.8)$ & $15(12.4)$ & $3(2.9)$ & \\
\hline
\end{tabular}

${ }^{a} p$-values were obtained from one-way ANOVA for continuous variables and Pearson's chi-square test for categorical variables $B C$ breast cancer 
Table 2 Participant characteristics and family health history parameters according to GC recommendation

\begin{tabular}{|c|c|c|c|c|}
\hline Characteristics & $\begin{array}{l}\text { Completed } \\
(n=102)\end{array}$ & $\begin{array}{l}\text { GC recommendation } \\
(n=66)\end{array}$ & $\begin{array}{l}\text { No GC recommendation } \\
(n=36)\end{array}$ & $p$-value \\
\hline Mean age at enrollment ${ }^{\mathrm{a}}$ (SD) & $55.7(9.0)$ & $52.3(7.8)$ & $61.9(7.7)$ & $<0.001$ \\
\hline Mean age at $\mathrm{BC}$ diagnosis $^{\mathrm{a}}(\mathrm{SD})$ & $52.5(9.2)$ & $48.5(7.5)$ & $59.9(7.2)$ & $<0.001$ \\
\hline Mean years from $B C$ diagnosis to enrollment ${ }^{a}(S D)$ & $3.2(3.7)$ & $3.8(4.2)$ & $2.0(2.1)$ & 0.004 \\
\hline Mean Manchester score ${ }^{a}$ (SD) & $4.1(4.3)$ & $5.7(4.2)$ & $1.2(2.7)$ & $<0.001$ \\
\hline Mean pedigree size ${ }^{\mathrm{b}, \mathrm{c}}(\mathrm{SD})$ & $10.7(3.6)$ & $10.7(3.5)$ & $10.7(3.6)$ & 0.986 \\
\hline Mean \% relatives with unknown history ${ }^{\mathrm{b}}$ (SD) & $28.9(19.5)$ & $27.3(17.7)$ & $31.7(22.4)$ & 0.390 \\
\hline Mean \% relatives with cancer history ${ }^{\mathrm{b}}(\mathrm{SD})$ & $15.2(13.6)$ & $16.9(14.2)$ & $12.0(11.9)$ & 0.093 \\
\hline Mean \% relatives with age of cancer diagnosis reported ${ }^{\mathrm{b}, \mathrm{d}}(\mathrm{SD})$ & $93.2(16.7)$ & $91.9(17.5)$ & $96.0(14.6)$ & 0.246 \\
\hline Race $^{a}$ & & & & 0.425 \\
\hline Chinese & $67(65.7)$ & $45(68.2)$ & $22(61.1)$ & \\
\hline Malay & $17(16.7)$ & $8(12.1)$ & $9(25.0)$ & \\
\hline Indian & $7(6.9)$ & $5(7.6)$ & $2(5.6)$ & \\
\hline Others & $11(10.8)$ & $8(12.1)$ & $3(8.3)$ & \\
\hline Breast Cancer stage ${ }^{a}$ & & & & 0.760 \\
\hline 0 & $4(3.9)$ & $3(4.5)$ & $1(2.8)$ & \\
\hline 1 & $20(19.6)$ & $15(22.7)$ & $5(13.9)$ & \\
\hline$\|$ & $46(45.1)$ & $28(42.4)$ & $18(50.0)$ & \\
\hline III & $12(11.8)$ & $7(10.6)$ & $5(13.9)$ & \\
\hline IV & $17(16.7)$ & $12(18.2)$ & $5(13.9)$ & \\
\hline Unknown & $3(2.9)$ & $1(1.5)$ & $2(5.6)$ & \\
\hline GC referral from clinical provider ${ }^{a}$ & & & & $<0.001$ \\
\hline Yes & $24(23.5)$ & $24(36.4)$ & 0 & \\
\hline No & $78(76.5)$ & $42(63.6)$ & $36(100.0)$ & \\
\hline Clinical provider ${ }^{\mathrm{a}}$ & & & & 0.902 \\
\hline Provider A & $38(37.3)$ & $22(33.3)$ & $16(44.4)$ & \\
\hline Provider B & $36(35.3)$ & $25(37.9)$ & $11(30.6)$ & \\
\hline Provider C & $8(7.8)$ & $6(9.1)$ & $2(5.6)$ & \\
\hline Provider D & $7(6.9)$ & $4(6.1)$ & $3(8.3)$ & \\
\hline Provider $\mathrm{E}$ & $7(6.9)$ & $5(7.6)$ & $2(5.6)$ & \\
\hline Provider $F$ & $3(2.9)$ & $2(3.0)$ & $1(2.8)$ & \\
\hline Provider G & $3(2.9)$ & $2(3.0)$ & $1(2.8)$ & \\
\hline
\end{tabular}

GC Genetic Counselling, SD Standard Deviation, BC Breast cancer

*(\%) refers to the proportion of participants among those with GC referral

${ }^{a} p$-values were obtained from Pearson's chi-square test for categorical variables and independent-

samples t-test for continuous variables $(p<0.05)$

${ }^{b} p$-values were obtained from Wilcoxon-rank sum test as FHH parameters not normally distributed $(p<0.05)$

cExcluding the participant

d Restricted to families with at least one relative with cancer, excluding cancer types without age of diagnosis reported. If relative has more than 1 cancer type reported, age is reported for at least one of those

in clinical justification for GC recommendation between those who were or were not referred for GC.

\section{Participant feedback on using a patient-facing risk assessment platform}

In the post-risk assessment survey, the majority of participants reported being very satisfied with the platform
$(66.7 \%)$ and the majority were likely to recommend it to others $(68.6 \%)$ (Table 7$)$. Related to the user experience, most participants found it to be easy to use $(86.3 \%)$, the questions did not make most feel anxious $(88.2 \%)$, and almost all found the questions easy to understand (98.0\%). Regarding preparedness of participants, the majority found the FHH collection worksheet to be helpful (75.5\%). However, most did not talk to relatives before 


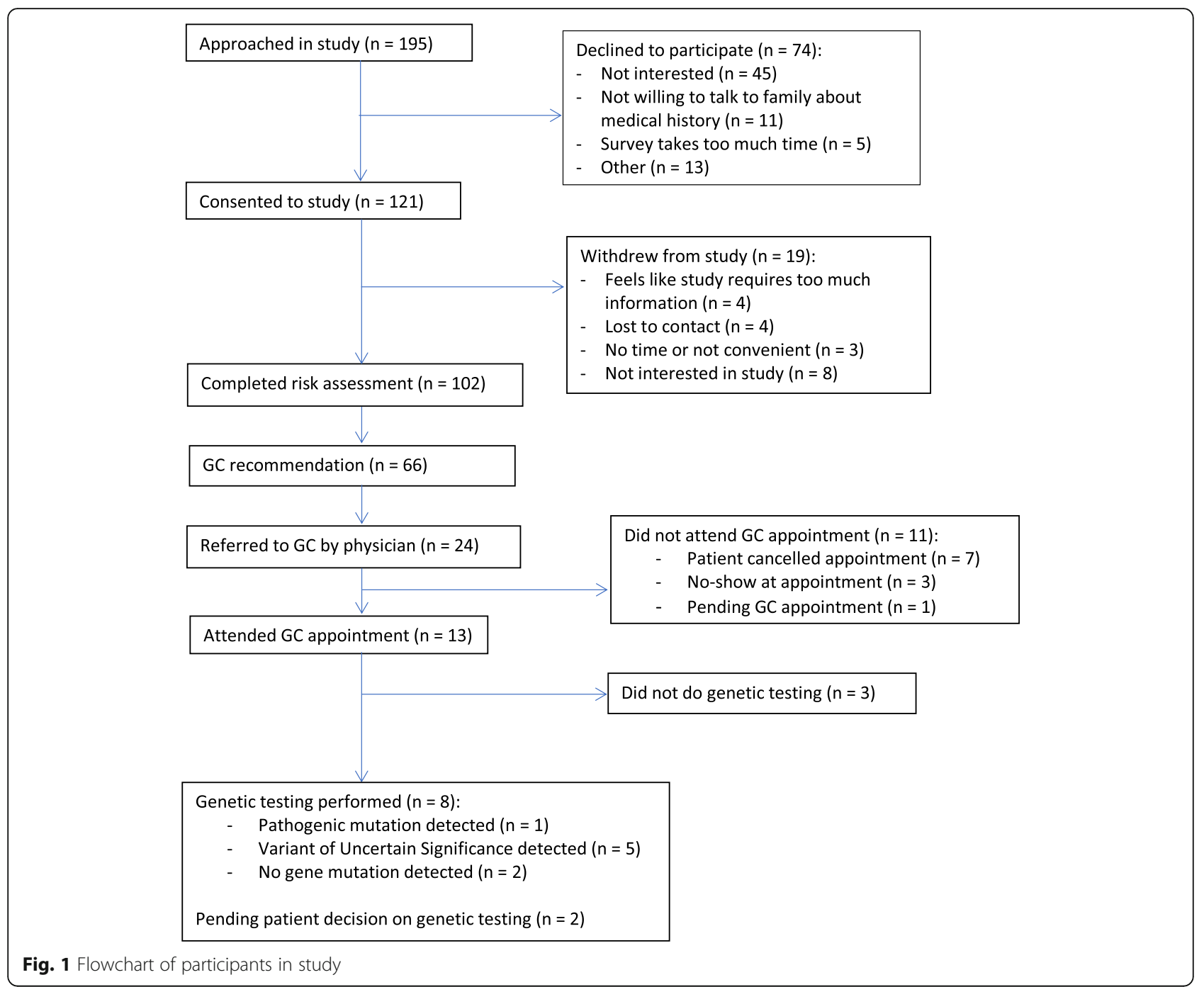

entering FHH data (66.7\%), and the majority did not feel they had enough information about some of their relatives $(76.5 \%)$. Regarding overall experience and benefits, $84.3 \%$ found completing the risk assessment platform to be a useful experience while $34.2 \%$ of participants learned a lot about their $\mathrm{FHH}$ that they did not know before. The majority of participants reported being more aware of their health risks after completing the risk assessment $(83.3 \%)$.

Participants were more likely to rate the risk assessment platform as easy to use if they reported a lower proportion of relatives with unknown history $(26.1 \%$ unknown history in those who reported the risk assessment as easy to use vs. $49.5 \%$ unknown history in those who found the risk assessment difficult, $\mathrm{p}=0.01$ ). Those with a lower proportion of relatives with cancer and those who did not receive a GC recommendation reported greater satisfaction with the risk assessment platform $(\mathrm{p}=0.002$ and $\mathrm{p}<0.001$ respectively).

\section{Discussion}

Our study evaluated the impact of a web-based patientfacing $\mathrm{FHH}$ risk assessment platform on identifying breast cancer patients with potential hereditary cancer syndromes and its effects on care delivery. This study demonstrates that patient-facing FHH risk assessment platforms can be implemented into oncology settings, with strong patient support. We found that a significant proportion of breast cancer study participants are at-risk for hereditary cancer syndromes. Yet, only one-third were referred for GC by their providers and only half of those referred attended the GC session. Of those who attended, $62 \%$ completed testing and a large majority of those tested were found with a VUS or pathogenic variant. These findings are similar to what has been observed when implementing standardized risk assessment within the primary care environment. In those studies, a significant proportion of the population was found to be at risk for hereditary cancer syndromes [27, 30, 34, 40] 
Table 3 Associations between participant characteristics and GC recommendation from multivariate logistic regression

\begin{tabular}{lll}
\hline Characteristics & $\begin{array}{l}\text { GC recommendation } \\
(\boldsymbol{n}=\mathbf{6 6}) \\
\text { OR }(\mathbf{9 5} \% \mathrm{CI})^{\mathbf{a}}\end{array}$ & $\boldsymbol{p}$-value \\
\hline $\begin{array}{l}\text { Age at enrollment } \\
\text { Mean }(95 \% \mathrm{CI})\end{array}$ & $-0.17(-0.26,-0.08)$ & 0.001 \\
Manchester score & $0.35(0.15,0.55)$ & $<0.001$ \\
\% relatives with cancer history & $0.06(0.01,0.11)$ & 0.017 \\
Race & $-1.17(-2.90,0.56)$ & 0.189 \\
Malay & $0.74(-1.92,3.40)$ & 0.584 \\
Indian & $-0.42(-2.50,1.66)$ & 0.693 \\
Others & Ref & \\
Chinese & & \\
Overall BC staging & Ref & 0.801 \\
0 & $0.67(-4.55,5.89)$ & 0.836 \\
I & $-0.53(-5.55,4.49)$ & 0.788 \\
II & $0.70(-4.43,5.84)$ & 0.950 \\
III & $0.17(-4.95,5.28)$ & \\
IV &
\end{tabular}

GC Genetic Counselling, OR Odds Ratio, CI Confidence Interval, $B C$ Breast

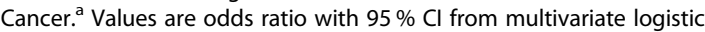
regression analysis.

(though lower than in a population pre-selected for having breast cancer as in this study) but as in this study, while there is some uptake of risk recommendations, there remain challenges to be addressed to improve clinical impact $[32,41]$.

FHH entered and participant feedback on risk assessment Overall the quality of the $\mathrm{FHH}$ entered by participants was good. Those with a GC recommendation trended towards a higher proportion of relatives with cancer history, were younger, and had higher Manchester scores. This demonstrates that the risk assessment platform was performing as intended as risk algorithms were based on current practice guidelines, which recommend breast cancer patients diagnosed at a young age and/or with family members with certain cancer characteristics to undergo GC [17]. Those found to be at risk did not differ in race, assigned clinical provider, or quality of $\mathrm{FHH}$ data entered, which supports a lack of bias in the tool and that risk identification was not simply due to bias towards participants knowing their FHH better than those not found to be at risk.

Participant feedback on using the risk assessment platform showed strong participant acceptance, with the majority reporting a high ease of use, ease of understanding and no anxiety. Despite being provided with educational materials beforehand to facilitate $\mathrm{FHH}$ collection, $66.7 \%$ of participants did not talk to relatives about $\mathrm{FHH}$ before using the platform and hence,
Table 4 Participant characteristics by GC referral status among participants with a GC recommendation

\begin{tabular}{|c|c|c|c|}
\hline Characteristics & $\begin{array}{l}\text { GC referral } \\
(\%) \\
(n=24)\end{array}$ & $\begin{array}{l}\text { No GC } \\
\text { referral (\%) } \\
(n=42)\end{array}$ & $\begin{array}{l}p \text { - } \\
\text { value }^{a}\end{array}$ \\
\hline Mean age at enrollment (SD) & $51.5(9.5)$ & $52.7(6.7)$ & 0.563 \\
\hline Mean age at diagnosis (SD) & $47.8(8.8)$ & $48.9(6.7)$ & 0.626 \\
\hline $\begin{array}{l}\text { Mean years from diagnosis to } \\
\text { enrollment (SD) }\end{array}$ & $3.6(4.8)$ & $3.9(3.8)$ & 0.825 \\
\hline Race & & & 0.707 \\
\hline Chinese & $15(62.5)$ & $30(71.4)$ & \\
\hline Malay & $3(12.5)$ & $5(11.9)$ & \\
\hline Indian & $3(12.5)$ & $2(4.8)$ & \\
\hline Others & $3(12.5)$ & $5(11.9)$ & \\
\hline Breast Cancer stage & & & 0.488 \\
\hline 0 & $2(8.3)$ & $1(2.4)$ & \\
\hline 1 & $6(25.0)$ & $10(21.4)$ & \\
\hline$\|$ & $10(41.7)$ & $18(42.9)$ & \\
\hline III & $3(12.5)$ & $4(9.5)$ & \\
\hline IV & $2(8.3)$ & $10(23.8)$ & \\
\hline Unknown & $1(4.2)$ & 0 & \\
\hline Clinical provider & & & 0.036 \\
\hline Provider A & $13(54.2)$ & $9(21.4)$ & \\
\hline Provider B & $3(12.5)$ & $22(52.4)$ & \\
\hline Provider C & $3(12.5)$ & $3(7.1)$ & \\
\hline Provider D & $2(8.3)$ & $2(4.8)$ & \\
\hline Provider $\mathrm{E}$ & $2(8.3)$ & $3(7.1)$ & \\
\hline Provider $F$ & 0 & $2(4.8)$ & \\
\hline Provider G & $1(4.2)$ & $1(2.4)$ & \\
\hline
\end{tabular}

GC Genetic Counselling, Cl Confidence Interval

a $p$-values were obtained from Pearson's chi-square test for categorical

variables or independent samples t-test for continuous variables $(p<0.05)$

majority did not have enough information about some relatives when completing it. This suggests that other barriers are present, other than lack of materials to facilitate $\mathrm{FHH}$ collection, that hinders patients' preparedness to provide FHH. Despite this, most participants felt they benefited from the risk assessment; they were more aware of their health risks and found it to be useful.

\section{GC referral from clinical provider}

The significant number of previously unidentified at-risk patients meeting practice guidelines for GC in this study demonstrates the need for more systematic and comprehensive $\mathrm{FHH}$ risk assessment within current oncology practice. Although it is recommended that clinical providers refer patients for genetic counselling early on in their treatment for timely management,[42, 43] we found that patients with GC recommendation frequently were many years out from their breast cancer diagnoses. 
Table 5 Associations between participant characteristics and GC referral among those with a GC recommendation from multivariate logistic regression

\begin{tabular}{lll}
\hline Characteristics & $\begin{array}{l}\text { GC referral } \\
(\boldsymbol{n}=\mathbf{2 4}) \\
\text { OR }(\mathbf{9 5} \% \mathbf{C l})^{\mathbf{a}}\end{array}$ & p-value \\
\hline $\begin{array}{l}\text { Age at enrollment } \\
\text { Mean }(95 \% \mathrm{Cl})\end{array}$ & $-0.02(-0.10,0.05)$ & 0.546 \\
Race & & \\
Malay & $-0.10(-1.94,1.75)$ & 0.919 \\
Indian & $1.46(-0.56,3.49)$ & 0.176 \\
Others & $-0.03(-1.75,1.70)$ & 0.976 \\
Chinese & Ref & \\
Overall BC staging & & \\
0 & Ref & 0.482 \\
I & $-1.03(-3.89,1.84)$ & 0.308 \\
II & $-1.45(-4.25,1.34)$ & 0.602 \\
III & $-0.83(-3.92,2.27)$ & 0.119 \\
IV & $-2.41(-5.44,0.62)$ & \\
\hline
\end{tabular}

GC Genetic Counselling, OR Odds Ratio, Cl Confidence Interval, $B C$ Breast Cancer

${ }^{\mathrm{a}}$ Values are odds ratio with $95 \% \mathrm{Cl}$ from multivariate logistic regression analysis.

Even after identification, barriers remain in the referral process. Of the 67 participants with a GC recommendation, 43 were not referred for GC. There was no obvious difference in clinical justification for GC between those with and without GC referral, but some clinical providers were more likely to refer than others. Rather than clinical factors, the significant proportion of participants that were not referred was likely due to a combination of patient and provider factors. In previous studies, provider barriers to referring patients for genetic services were lack of awareness of risk factors, hereditary conditions and genetic services (including unknown or assumed high costs of genetic testing), inadequate $\mathrm{FHH}$ assessment and inadequate referral coordination.[44-46] In order to increase appropriate GC referrals further, more must be done to integrate risk assessment platforms into current workflows and referral processes, and to increase provider awareness of hereditary conditions. While risk assessment was offered systematically to any eligible patient, it was not integrated into the EMR and this lack of integration may have resulted in a reduced impact of risk report results on clinical care. Additional barriers to uptake of GC recommendations by clinicians and participants are being explored through an ongoing qualitative aim of this study. Not unlike other public health measures, real change will require change at health policy levels and systematic implementation with prioritization of proactive care over a traditional reactive care model.
Table 6 Clinical justification for GC recommendation according to GC referral status

\begin{tabular}{|c|c|c|c|}
\hline & $\begin{array}{l}\text { All with GC } \\
\text { recommendation } \\
(n=66)\end{array}$ & $\begin{array}{l}\text { GC referral } \\
(n=24)\end{array}$ & $\begin{array}{l}\text { No GC } \\
\text { referral }(n=42)\end{array}$ \\
\hline \multicolumn{4}{|c|}{ Personal medical history } \\
\hline $\begin{array}{l}\text { BC diagnosis at } \\
\text { age } \leq 50\end{array}$ & 41 & 18 & 23 \\
\hline $\begin{array}{l}\text { Bilateral breast } \\
\text { cancer }\end{array}$ & 2 & 2 & 0 \\
\hline $\begin{array}{l}\text { TNBC diagnosis } \\
\text { age }<60\end{array}$ & 3 & 2 & 1 \\
\hline $\begin{array}{l}\text { Ovarian cancer } \\
\text { diagnosis }\end{array}$ & 1 & 1 & 0 \\
\hline $\begin{array}{l}\text { Endometrial cancer } \\
\text { diagnosed at age }< \\
50\end{array}$ & 1 & 0 & 1 \\
\hline \multicolumn{4}{|l|}{ Family history } \\
\hline $\begin{array}{l}\geq 1 \text { relative with } \mathrm{Li}- \\
\text { Fraumeni syndrome } \\
\text { related cancer }+ \\
\text { Personal } \mathrm{BC} \text { diag- } \\
\text { nosis at age } \leq 45\end{array}$ & 9 & 1 & 8 \\
\hline $\begin{array}{l}\geq 1 \text { relative with Li- } \\
\text { Fraumeni syndrome } \\
\text { related cancer at } \\
\text { age } \leq 45\end{array}$ & 5 & 3 & 2 \\
\hline $\begin{array}{l}\geq 3 \text { family } \\
\text { members with } \\
\text { same cancer }\end{array}$ & 2 & 0 & 2 \\
\hline $\begin{array}{l}\geq 2 \text { relatives with } \\
\text { colorectal cancer }\end{array}$ & 1 & 0 & 1 \\
\hline $\begin{array}{l}\geq 3 \text { cases of Lynch } \\
\text { syndrome related } \\
\text { cancer in family }\end{array}$ & 5 & 1 & 4 \\
\hline $\begin{array}{l}\geq 2 \text { cases of breast, } \\
\text { ovarian, pancreatic } \\
\text { or prostate cancer } \\
\text { in family }\end{array}$ & 5 & 1 & 4 \\
\hline $\begin{array}{l}\geq 1 \text { FDR with breast } \\
\text { cancer at age } \leq 50\end{array}$ & 3 & 2 & 1 \\
\hline $\begin{array}{l}\geq 1 \text { FDR with } \\
\text { colorectal cancer at } \\
\text { age }<50\end{array}$ & 3 & 2 & 1 \\
\hline $\begin{array}{l}\geq 1 \text { FDR with } \\
\text { ovarian cancer }\end{array}$ & 2 & 0 & 2 \\
\hline \multicolumn{4}{|l|}{ Risk score } \\
\hline $\begin{array}{l}\text { Manchester risk } \\
\text { score meets criteria }\end{array}$ & 13 & 6 & 7 \\
\hline
\end{tabular}

GC Genetic Counselling, TNBC Triple Negative Breast Cancer, FDR First Degree Relative

Although not captured systematically, study clinical providers recorded in the EMR for at least four participants that GC referral was discussed after receiving a GC recommendation, but clinical referral was not made due to patient preferences. Additionally, of the 24 patients with a GC referral, only 13 (54.2\%) attended their 
Table 7 Participant responses in post-risk assessment satisfaction survey

\begin{tabular}{|c|c|c|}
\hline Questions & Responses & $\begin{array}{l}\text { Completed } \\
(\%) \\
(n=102)\end{array}$ \\
\hline \multirow[t]{6}{*}{ Q1. Satisfaction with risk assessment platform experience } & Mean $(95 \% \mathrm{Cl})$ & $3.8(3.6-3.9)$ \\
\hline & 1 - Very poor & $1(1.0)$ \\
\hline & $\begin{array}{l}2 \text { - Somewhat } \\
\text { unsatisfactory }\end{array}$ & $4(3.9)$ \\
\hline & 3 - About average & $29(28.4)$ \\
\hline & 4 - Very satisfactory & $53(52.0)$ \\
\hline & 5 - Superior & $15(14.7)$ \\
\hline \multirow[t]{6}{*}{ Q2. Likelihood to recommend risk assessment platform to others } & Mean $(95 \% \mathrm{Cl})$ & $3.9(3.7-4.0)$ \\
\hline & 1 - Not likely & $1(0.8)$ \\
\hline & 2 - Unlikely & $6(5.0)$ \\
\hline & 3 - Somewhat likely & $25(24.5)$ \\
\hline & 4 - Likely & $45(44.1)$ \\
\hline & 5 - Very likely & $25(24.5)$ \\
\hline \multirow[t]{2}{*}{ The risk assessment platform was easy to use. ${ }^{\text {a }}$} & Yes & $88(86.3)$ \\
\hline & No & $7(6.9)$ \\
\hline \multirow[t]{2}{*}{ Answering the questions made me anxious. ${ }^{a}$} & Yes & $10(9.8)$ \\
\hline & No & $90(88.2)$ \\
\hline \multirow[t]{2}{*}{ The questions were easy to understand. ${ }^{a}$} & Yes & $100(98.0)$ \\
\hline & No & $1(1.0)$ \\
\hline \multirow[t]{2}{*}{ The family history worksheet used to help collect information was helpful. ${ }^{a}$} & Yes & $77(75.5)$ \\
\hline & No & $5(4.9)$ \\
\hline \multirow[t]{2}{*}{ I talked with relatives about our family's health history before using the risk assessment platform. ${ }^{\text {a }}$} & Yes & $32(31.4)$ \\
\hline & No & $68(66.7)$ \\
\hline \multirow{2}{*}{$\begin{array}{l}\text { I didn't have enough information about some people in my family when completing the risk assessment } \\
\text { platform. }\end{array}$} & Yes & $78(76.5)$ \\
\hline & No & $22(21.6)$ \\
\hline \multirow[t]{2}{*}{ Completing the risk assessment platform was a useful experience. ${ }^{a}$} & Yes & $86(84.3)$ \\
\hline & No & $5(4.9)$ \\
\hline \multirow[t]{2}{*}{ I learned a lot about my family's health history that I did not know. ${ }^{a}$} & Yes & $41(34.2)$ \\
\hline & No & $45(44.1)$ \\
\hline \multirow[t]{2}{*}{ I am more aware of my health risks. ${ }^{a}$} & Yes & 85 (83.3) \\
\hline & No & $9(8.8)$ \\
\hline
\end{tabular}

aPercentages of participants that responded 'don't know' were not reflected in this table.

appointments. In previous studies, patient barriers to GC attendance were cost, emotional concerns, family concerns and low perceived personal relevance [47-49]. The cost of genetic testing for hereditary cancer conditions in Singapore is at present an "out-of-pocket" [49] expense and has been reported as a barrier to referral and uptake $[46,50]$. In a local study, it was found that subsidizing the cost of genetic testing resulted in an increase in uptake rate and could be cost-saving [49]. This suggests that raising awareness of the need for GC among patients may be insufficient and that risk assessment should be paired with interventions targeting specific barriers to GC. Prior intervention studies aiming to increase genetic testing uptake [51-56] by providing participants with more information on genetic testing through various avenues (e.g. educational resources, interactive program) reported intervention participants being more informed about genetic testing with improved knowledge. However, the interventions did not impact significantly the uptake of genetic testing.

Of the referred, 13 (54.2\%) attended their GC appointments and eight (61.5\% of attended) went through genetic testing. The medical and family health history of the three participants that declined testing did not meet the 
National Comprehensive Cancer Network (NCCN) criteria for $B R C A 1 / 2$ testing [57] but testing of other relevant genes was offered by genetic counsellors.

\section{Limitations}

There were limitations to the conclusions which can be drawn from this study. It was a small sample size given that it was a pilot to assess feasibility only. Outcomes may have been impacted by survivor bias as we offered enrollment to any patient with breast cancer history and no prior referral to GC and/or testing, hence, there was a mix of participants with incident and prevalent breast cancer cases. Additionally, excluding those previously tested could have resulted in a bias towards selecting participants with more anxiety towards GC. If evaluating in an unselected population with incident breast cancer, GC referral and testing rates might have been higher. The web-based nature of the FHH risk assessment platform could also have affected the uptake and study progression of individuals with lower comfort with technology although a coordinator was available to assist. Finally, the healthcare setting in which a study is performed has the potential to limit its applicability to other healthcare settings as other countries may have different models of care delivery and financing which impact uptake.

\section{Conclusions}

The implementation of a risk assessment platform in oncology clinics identified a significant proportion of breast cancer patients with previously unidentified hereditary cancer risk and facilitated GC referrals. Further evaluation of the barriers and understanding of how to make risk assessment more accessible to patients and clinical providers is warranted, in order to optimize the use of a systematic risk assessment in oncology clinical practice and improve care.

\section{Abbreviations \\ FHH: Family health history; GC: Genetic counselling; EMR: Electronic medical record; VUS: Variant of uncertain significance; OR: Odds ratio}

\section{Acknowledgements}

We would like to thank all participants and involved clinical providers and staff in National Cancer Centre Singapore and KK Women's and Children's Hospital for their participation in this study, without which this study would not be possible.

\footnotetext{
Authors' contributions

SF was involved in IRB approval, collection and analysis of the data, drafting of the manuscript. RW contributed to design of the study, application for funding, obtaining IRB approval, oversight of research team, directing of statistical analysis, and was a major contributor to the drafting and editing of the manuscript. RM contributed to data analysis and manuscript review and editing. JG contributed to data collection. GS contributed to study design and manuscript review and editing. DM contributed to IRB approval and study initiation. LO contributed to study design, application for funding, oversight of study implementation, and manuscript review and editing. JN contributed to IRB approval, study initiation, oversight of research team, and
}

manuscript review and editing. All authors read and approved the final manuscript.

\section{Funding}

This study was funded by Duke/Duke-NUS Research Collaboration Pilot Project Award 2017/0033. The funder did not participate in the design of the study, collection, analysis, or interpretation of data, or in writing or approving the manuscript

\section{Availability of data and materials}

The datasets used and/or analyzed during the current study are available from the corresponding author on reasonable request.

\section{Declarations}

\section{Ethics approval and consent to participate}

The study was approved by Duke University IRB (Pro 00087654) and SingHealth-Centralized Institutional Review Board (CIRB 2018/2046). Written informed consent was obtained from the participants at recruitment.

\section{Consent for publication}

Not applicable.

\section{Competing interests}

RW, LO, and GG report a potential conflict of interest as they are co-founders of a company, MeTree\&You that in the future will provide MeTree as a clinical service. MeTree\&You has not and will not receive any direct financial gain from this study or publication. All other authors declare no conflicts of interest.

\section{Author details}

${ }^{1}$ Cancer Genetics Service, Division of Medical Oncology, National Cancer Centre Singapore, Singapore, Singapore. ${ }^{2}$ Centre for Applied Genomics and Precision Medicine, Department of Medicine, Duke University School of Medicine, 304 Research Dr. Box 90141, Office 264, North Carolina 27708 Durham, USA. ${ }^{3}$ Department of Medicine, Duke University School of Medicine, 304 Research Dr. Box 90141, Office 264, North Carolina 27708 Durham, USA. ${ }^{4}$ Program in Health Services and Systems Research, Duke-NUS Medical School, Singapore, Singapore. ${ }^{5}$ Lee Kong Chian School of Medicine, Nanyang Technological University, Singapore, Singapore.

Received: 4 December 2020 Accepted: 10 March 2021

Published online: 20 March 2021

\section{References}

1. Roos A, Byron SA. Genomics-Enabled Precision Medicine for Cancer. In: Von Hoff D, Han H, editors. Precis Med Cancer Ther Cancer Treat Res. vol 178. Springer, Cham; 2019. p. 137-69.

2. Tischler J, Crew KD, Chung WK. Cases in Precision Medicine: The Role of Tumor and Germline Genetic Testing in Breast Cancer Management. Ann Intern Med. 2019;1-7.

3. Maslov AY, Quispe-Tintaya W, Gorbacheva T, White RR, Vijg J. Highthroughput sequencing in mutation detection: A new generation of genotoxicity tests? Mutat Res. 2015;776:136-43.

4. Apostolou P, Fostira F. Hereditary breast cancer: The Era of new susceptibility genes. Biomed Res Int. 2013;2013.

5. Garber JE, Offit K. Hereditary cancer predisposition syndromes. J Clin Oncol. 2005;23:276-92.

6. ACMG Board of Directors. Clinical utility of genetic and genomic services: a position statement of the American College of Medical Genetics and Genomics. Genet Med. 2015;17:505-7.

7. Pruthi S, Heisey RE, Bevers TB. Chemoprevention for Breast Cancer. Ann Surg Oncol. 2015;22:3230-5.

8. Domchek SM, Friebel TM, Singer CF, Evans DG, Henry T, Isaacs C, et al, Association of Risk-Reducing Surgery in BRCA1 or BRCA2 Mutation Carriers with Cancer Risk and Mortality. JAMA. 2010;304:967-75.

9. Tung NM, Garber JE. BRCA1/2 testing: therapeutic implications for breast cancer management. Br J Cancer. 2018;119:141-52.

10. Fong PC, Boss DS, Yap TA, Tutt A, Wu P, Mergui-Roelvink M, et al. Inhibition of poly(ADP-ribose) polymerase in tumors from BRCA mutation carriers. N Engl J Med United States. 2009;361:123-34. 
11. Kamel D, Gray C, Walia JS, Kumar V. PARP Inhibitor Drugs in the Treatment of Breast, Ovarian, Prostate and Pancreatic Cancers: An Update of Clinical Trials. Curr Drug Targets United Arab Emirates. 2018;19:21-37.

12. Pilié PG, Gay CM, Byers LA, O'Connor MJ, Yap TA. PARP inhibitors: Extending benefit beyond BRCA-mutant cancers. Clin Cancer Res. 2019;25:3759-71.

13. Evans DG, Graham J, O'Connell S, Arnold S, Fitzsimmons D. Familial breast cancer: Summary of updated NICE guidance. BMJ. British Medical Journal Publishing Group; 2013.

14. Provenzale D, Gupta S, Ahnen DJ, Bray T, Cannon JA, Cooper G, et al. Genetic/familial high-risk assessment: Colorectal version 1.2016: Clinical practice guidelines in oncology. JNCCN J Natl Compr Cancer Netw Harborside Press. 2016;14:1010-30.

15. Obeng AO, Fei K, Levy KD, Elsey AR, Pollin TI, Ramirez AH, et al. Physicianreported benefits and barriers to clinical implementation of genomic medicine: A multi-site iGNITE-network survey. J Pers Med. 2018;8.

16. Manolio TA, Rowley R, Williams MS, Roden D, Ginsburg GS, Bult C, et al. Opportunities, resources, and techniques for implementing genomics in clinical care. Lancet. Elsevier Ltd; 2019;6736:1-10.

17. Hampel H, Bennett RL, Buchanan A, Pearlman R, Wiesner GL. A practice guideline from the American College of Medical Genetics and Genomics and the National Society of Genetic Counselors: Referral indications for cancer predisposition assessment. Genet Med. 2015;17:70-87.

18. Smith RA, Cokkinides V, Brawley OW. Cancer screening in the United States, 2012: A review of current American Cancer Society guidelines and current issues in cancer screening. CA Cancer J Clin. 2012;62:129-42.

19. Ginsburg GS, Wu RR, Orlando LA. Family health history: underused for actionable risk assessment. Lancet. 2019:394:596-603.

20. Murff HJ, Greevy RA, Syngal S. The Comprehensiveness of Family Cancer History Assessments in Primary Care. Public Health Genomics. 2007;10:17480 .

21. McVeigh TP, Sundar R, Diamantis N, Kaye SB, Banerji U, Lopez JS, et al. The role of genomic profiling in adolescents and young adults (AYAs) with advanced cancer participating in phase I clinical trials. Eur J Cancer. 2018;95: 20-9.

22. McGuinness JE, Trivedi MS, Vanegas A, Colbeth H, Sandoval R, Kukafka R, et al. Decision support for family history intake to determine eligibility for BRCA testing among multiethnic women. J Clin Oncol American Society of Clinical Oncology. 2017;35:1586-6.

23. Audrain-McGovern J, Hughes C, Patterson F. Effecting behavior change: awareness of family history. Am J Prev Med Elsevier. 2003;24:183-9.

24. Watson EK, Shickle D, Qureshi N, Emery J, Austoker J. The new genetics and primary care: GPs' views on their role and their educational needs. Fam Pract Narnia. 1999:16:420-5.

25. Reid GT, Walter FM, Brisbane JM, Emery JD. Family History Questionnaires Designed for Clinical Use: A Systematic Review. Public Health Genomics. 2009;12:73-83.

26. Qureshi N, Carroll JC, Wilson B, Santaguida P, Allanson J, Brouwers M, et al. The current state of cancer family history collection tools in primary care: a systematic review. Genet Med. 2009;11:495-506.

27. O'Neill SM, Rubinstein WS, Wang C, Yoon PW, Acheson LS, Rothrock N, et al. Familial risk for common diseases in primary care: the Family Healthware Impact Trial. Am J Prev Med Netherlands. 2009;36:506-14.

28. Wu RR, Himmel TL, Buchanan AH, Powell KP, Hauser ER, Ginsburg GS, et al Quality of family history collection with use of a patient facing family history assessment tool. BMC Fam Pract BMC Family Practice. 2014:15:1-8.

29. Sweet KM, Bradley TL, Westman JA. Identification and Referral of Families at High Risk for Cancer Susceptibility. J Clin Oncol American Society of Clinical Oncology (ASCO). 2002;20:528-37.

30. Cohn WF, Ropka ME, Pelletier SL, Barrett JR, Kinzie MB, Harrison MB, et al. Health Heritage $\odot$, a web-based tool for the collection and assessment of family health history: Initial user experience and analytic validity. Public Health Genomics. 2010;13:477-91.

31. Orlando LA, Buchanan AH, Hahn SE, Christianson C, Powell K, Skinner CS, et al. Development and Validation of a Primary Care-Based Family Health History and Decision Support Program (MeTree) HHS Public Access. N C Med J. 2013;74:287-96.

32. Orlando LA, Wu RR, Myers RA, Buchanan AH, Henrich VC, Hauser ER, et al. Clinical utility of a Web-enabled risk-assessment and clinical decision support program. Genet Med IOP Publishing. 2016;18:1020-8.

33. Wu RR, Myers RA, Sperber N, Voils Cl, Neuner J, McCarty CA, et al. Implementation, adoption, and utility of family health history risk assessment in diverse care settings: evaluating implementation processes and impact with an implementation framework. Genet Med Springer US. 2019;21:331-8

34. Orlando L, Wu R, Myers R, Neuner J, McCarty C, Haller I, et al. At the intersection of precision medicine and population health: An implementation-effectiveness study of family health history based systematic risk assessment in primary care. BMC Health Serv Res. 2020.

35. Curran GM, Bauer M, Mittman B, Pyne JM, Stetler C. Effectivenessimplementation hybrid designs: combining elements of clinical effectiveness and implementation research to enhance public health impact. Med Care. 2012;50:217-26.

36. Kast K, Schmutzler RK, Rhiem K, Kiechle M, Fischer C, Niederacher D, et al. Validation of the Manchester scoring system for predicting BRCA1/2 mutations in 9,390 families suspected of having hereditary breast and ovarian cancer. Int J cancer United States. 2014;135:2352-61.

37. Wu RR, Orlando LA, Himmel TL, Buchanan AH, Powell KP, Hauser ER, et al. Patient and primary care provider experience using a family health history collection, risk stratification, and clinical decision support tool: A type 2 hybrid controlled implementation-effectiveness trial. BMC Fam Pract BMC Family Practice. 2013;14:1.

38. Wong WK. Population Trends 2018 [Internet]. Dep. Stat. Minist. Trade Ind. Repub. Singapore. 2018. Available from: http://www.singstat.gov.sg/.

39. National Registry of Disease Singapore. Trends of Female Breast Cancer in Singapore 2006-2010. A Publ Natl Regist Dis Off Singapore Heal Factsheet, July 27, 2012, INP-12-3. 2012;2012:2006-10.

40. Carroll JC, Campbell-Scherer D, Permaul JA, Myers J, Manca DP, Meaney C, et al. Assessing family history of chronic disease in primary care: Prevalence, documentation, and appropriate screening. Can Fam Physician. 2017;63:e58-67.

41. Rubinstein WS, Acheson LS, O'Neill SM, Ruffin MT 4th, Wang C, Beaumont $J$, et al. Clinical utility of family history for cancer screening and referral in primary care: a report from the Family Healthware Impact Trial. Genet Med. 2011;13:956-65.

42. Daniels MS, Urbauer DL, Stanley JL, Johnson KG, Lu KH. Timing of BRCA1/ BRCA2 genetic testing in women with ovarian cancer. Genet Med. 2009;11: 624-8.

43. Knabben L, Imboden S, Mueller MD. Genetic testing in ovarian cancer Clinical impact and current practices. Horm Mol Biol Clin Investig. 2019;1-7.

44. Delikurt T, Williamson GR, Anastasiadou V, Skirton H. A systematic review of factors that act as barriers to patient referral to genetic services. Eur J Hum Genet. 2015;23:739-45.

45. Ow SGW, Yong YFL, Chieng WS, Phyu PS, Lee SC. Inadequate family history assessment by oncologists is an important physician barrier to referral for hereditary breast cancer evaluation. Clin Oncol. 2014;26:174-5.

46. Tan YY, Fitzgerald LJ. Barriers and motivators for referral of patients with suspected lynch syndrome to cancer genetic services: a qualitative study. J Pers Med Switzerland. 2014:4:20-34.

47. Willis AM, Smith SK, Meiser B, Ballinger ML, Thomas DM, Young M-A. Sociodemographic, psychosocial and clinical factors associated with uptake of genetic counselling for hereditary cancer: a systematic review. Clin Genet Denmark. 2017;92:121-33.

48. Chin TM, Tan SH, Lim SE, lau P, Yong WP, Wong SW, et al. Acceptance, motivators, and barriers in attending breast cancer genetic counseling in Asians. Cancer Detect Prev. 2005;29:412-8.

49. Li ST, Yuen J, Zhou K, Ishak NDB, Chen Y, Met-Domestici M, et al. Impact of subsidies on cancer genetic testing uptake in Singapore. J Med Genet. 2017; 54:254-9.

50. Qian E, Thong MK, Flodman P, Gargus J. A comparative study of patients' perceptions of genetic and genomic medicine services in California and Malaysia. J Community Genet Journal of Community Genetics. 2019;10:35161.

51. Green MJ, Biesecker BB, Mclnerney AM, Mauger D, Fost N. An interactive computer program can effectively educate patients about genetic testing for breast cancer susceptibility. Am J Med Genet. 2001;103:16-23.

52. Schwartz MD, Benkendorf J, Lerman C, Isaacs C, Ryan-Robertson A, Johnson L. Impact of educational print materials on knowledge, attitudes, and interest in BRCA1/BRCA2: Testing among Ashkenazi Jewish women. Cancer. 2001;92:932-40.

53. Wang C, Gonzalez R, Milliron KJ, Strecher VJ, Merajver SD. Genetic counseling for BRCA1/2: A randomized controlled trial of two strategies to facilitate the education and counseling process. Am J Med Genet. 2005:134 A:66-73. 
54. Miller SM, Fleisher L, Roussi P, Buzaglo JS, Schnoll R, Slater E, et al. Facilitating informed decision making about breast cancer risk and genetic counseling among women calling the NCl's Cancer Information Service. J Health Commun. 2005:10:119-36.

55. Wakefield CE, Meiser B, Homewood J, Taylor A, Gleeson M, Williams R, et al. A randomized trial of a breast/ovarian cancer genetic testing decision aid used as a communication aid during genetic counseling. Psychooncology. 2008:17:844-54.

56. Albada A, Van Dulmen S, Lindhout D, Bensing JM, Ausems MGEM. A previsit tailored website enhances counselees' realistic expectations and knowledge and fulfils information needs for breast cancer genetic counselling. Fam Cancer. 2012;11:85-95.

57. NCCN. Genetic / Familial High-Risk Assessment: Breast and Ovarian [Internet]. 2019 [cited 2020 Jan 31]. Available from: https://www.nccn.org/ store/login/login.aspx?ReturnURL=https://www.nccn.org/professionals/ physician_gls/pdf/genetics_bop.pdf.

\section{Publisher's Note}

Springer Nature remains neutral with regard to jurisdictional claims in published maps and institutional affiliations.

Ready to submit your research? Choose BMC and benefit from:

- fast, convenient online submission

- thorough peer review by experienced researchers in your field

- rapid publication on acceptance

- support for research data, including large and complex data types

- gold Open Access which fosters wider collaboration and increased citations

- maximum visibility for your research: over $100 \mathrm{M}$ website views per year

At BMC, research is always in progress.

Learn more biomedcentral.com/submissions 